\title{
Patrimonio cultural inmaterial en barrios informales de la Localidad de San Cristóbal en Bogotá - Colombia.
}

\section{Intangible cultural heritage in informal neighborhoods of the town of San Cristóbal in Bogotá - Colombia.}

\author{
Cortés-Garzón, Liliana ${ }^{1}$ \\ ${ }^{1}$ Directora Proyecto Sur, Colombia \\ ${ }^{1}$ lcortesgarzon@gmail.com / https://orcid.org/0000-0002-3289-5043
}

Recibido el 28 de febrero de 2021, aprobado el 09 de junio de 2021

RESUMEN | Esta investigación categoriza prácticas artísticas como patrimoniales (de carácter inmaterial) en la Localidad de San Cristóbal en Bogotá, Colombia. Las dinámicas culturales al interior de barrios, en su mayoría, de carácter informal, combina conocimientos y tradiciones de diversas regiones del país, por la migración de muchos de sus habitantes a la capital. Este proceso de mestizaje cultural, entre tradiciones regionales, populares y urbanas crea nuevos territorios festivos con identidades locales y saberes ancestrales en celebraciones y festividades dedicadas a la vida y a las memorias de nuevas generaciones urbanas, como estrategia de comunicación educativa, para la protección de patrimonios culturales inmateriales.

PALABRAS CLAVE | Patrimonio, cultura inmaterial, informalidad, localidad de San Cristóbal, Bogotá, Sur oriente

\begin{abstract}
This research categorizes artistic practices as patrimonial (of an immaterial nature) in the town of San Cristóbal in Bogotá, Colombia. The cultural dynamics within neighborhoods, mostly of an informal nature, combine knowledge and traditions of various regions of the country, due to the migration of many of its inhabitants to the capital. This process of cultural miscegenation, between regional, popular and urban traditions creates new festive territories with local identities and ancestral knowledge in celebrations and festivities dedicated to the life and memories of new urban generations, as an educational communication strategy, for the protection of heritage intangible cultural.
\end{abstract}

KEYWORD | Heritage, intangible culture, informality, San Cristóbal town, Bogotá, South East 


\section{Introducción}

El patrimonio cultural inmaterial se entiende como todas aquellas expresiones realizadas por un colectivo de personas que de manera autónoma realizan prácticas culturales que se constituyen en una serie de conocimientos que se transmiten de generación en generación en un territorio específico. El conocimiento que tienen tanto migrantes de sus tradiciones culturales, como los habitantes de periferias de ciudades en América Latina y de territorios del Sur del planeta, relacionan formas de conocimiento en asentamientos de carácter informal, con conocimientos que se trasmiten en culturas urbanas periféricas, en las cuales la movilidad (en la migración/ exclusión o desplazamiento), tiene elementos urbanos y rurales que generan sentimientos de vínculo entre el pasado, presente discontinuo y futuro posible, por lo general, de carácter comunitario.

Esta investigación, aborda patrimonios locales creados colectivamente, poco protegidos, en territorios de borde, aunque legalmente enunciados en el Sistema Nacional de Patrimonio en Colombia. Como tal, el sistema, incluye un conjunto de instancias públicas, que ejercen competencias sobre el patrimonio cultural de la Nación, por los bienes y manifestaciones del patrimonio cultural de la Nación, por los bienes de interés cultural y sus propietarios, usufructuarios a cualquier título y tenedores (Decreto Único Reglamentario 1080 de 2015 Nivel Nacional, 2015 SNPCN).

Este artículo, define como prácticas culturales, dentro de la categoría de patrimonio cultural inmaterial, aquellas que de manera colectiva usan y se producen en el espacio público y social de un lugar, en este caso, en el suroriente de la ciudad de Bogotá. Esta producción de un espacio habitado por generaciones de habitantes del suroriente define memorias colectivas en territorios de borde, dentro de la historia barrial, como una historia cultural de acuerdo a las formas de construcción de barrios de la localidad. Los barrios informales, tienen como característica en común, según ONU Hábitat, grandes áreas en las cuales, los habitantes no ostentan el derecho a la tenencia; pocos espacios públicos adaptados para su uso y disfrute; barrios que carecen de la prestación de mínimos servicios públicos; las viviendas están en zonas peligrosas o en riesgo, entre otras.

La pregunta central de investigación es ¿Las formas de asentamiento de barrios informales traen patrimonios culturales inmateriales que logran asentarse en el tiempo o construir nuevas prácticas culturales y artísticas que construyen un nuevo espacio cultural y urbano en los territorios de borde considerado patrimonial-inmaterial-? La búsqueda de este escrito es acercarse a dar posibles respuestas sobre como la producción de patrimonios culturales inmateriales, generan espacios urbanos culturales en la Localidad de San Cristóbal, suroriente de Bogotá. La investigación aborda conceptos centrales como la informalidad, la construcción de historias barriales a partir de experiencias culturales que se viven en territorios de borde de las ciudades, entre una búsqueda por encuentros comunitarios y colectividades que se activan a través de trabajos asociativos en periferias urbanas y bordes.

El artículo desarrolla entonces esta triple relación entre patrimonio cultural inmaterial, informalidad y producción de espacios culturales y urbanos en territorios de borde, no solamente desde las múltiples relaciones que pueden llegar a existir entre las problemáticas propuestas, su desarrollo y un acercamiento a posibles conclusiones que sugieren caminos de investigación a futuro. La relación entre patrimonio cultural inmaterial no excluye posibles patrimonios materiales, sin embargo, no son la característica principal de barrios en asentamientos informales, dado que la arquitectura y la planificación territorial, en lugares considerados como periferias, son escasas y tienen lógicas de funcionamiento distintas. 
La periferia como concepto ha sido utilizado en estudios realizados por Raúl Prebisch quien conceptualizó la dicotomía Centro/Periferia (C/P) en el ámbito económico plantea los cambios en los conceptos de auto centramiento (o crecimiento endógeno, o desarrollo hacia dentro) y extraversión (o desarrollo hacia fuera), "tal como fueron acuñados por Samir Amin o la CEPAL, entre otros" (Martínez, 2011 Pág. 32). Con los años y los cambios dados en los extremos de las ciudades el concepto periferia dio un giro y en la actualidad, hablar en singular del "centro y periferia" suena fuera de las realidades urbanas contemporáneas da paso al uso del plural, dada la complejidad cada vez mayor de los entornos urbanos de borde. Las periferias urbanas son estudiadas como áreas desordenadas y marginales en lugares que limitan con los exteriores de una ciudad, y este lugar les asigna características de dependencia de centros urbanos, con ciertas autonomías y autoconstrucciones no solamente arquitectónicas, sino también de carácter cultural y artístico.

Las periferias urbanas comprenden situaciones de borde metropolitano y barrios de carácter informal, que mantienen culturas migrantes en territorios suburbanizados, que adoptan culturas foráneas como las culturas urbanas, musicales, de modas, gastronomías rurales, festivales y formas de hablar que llevan en la actualidad, algunas décadas y que generan patrimonios inmateriales en transición en sectores urbanos en el caso de las localidades de San Cristóbal o Ciudad Bolívar en Bogotá. En este artículo se aborda el patrimonio inmaterial que se produce en el borde y se contextualiza desde los Estudios del Sur para su análisis teórico con algunos conceptos de la teoría decolonial. Los estudios del sur, se relacionan con las premisas decoloniales que presentan estudios desde una crítica a occidente y a las fuertes diferencias tanto sociales como ideológicas dadas como estructuras culturales después de la conquista, categorías estudiadas por los estudios sociales y humanísticos que abordan una crítica desde la perspectiva postcolonial que, a partir de una crítica intelectual, intenta develar el carácter colonial del pensamiento ilustrado en América desde el siglo XVIII, pero de igual manera aplicado a siglos posteriores, entiende y analiza formas de pensamiento coloniales en los gobernantes latinoamericanos y en sus ciudadanos.

La planificación territorial, tanto en territorios como en la organización de ciudades, es necesario ser analizada detalladamente en cada caso en particular. Lo urbano presenta un sometimiento a normas territoriales con paisajes que son ficticios, imaginados para territorios latinoamericanos, que implica dinámicas no solamente estatales, sino de auto reivindicación y autoconocimiento de las poblaciones que los habitan. En las ciudades latinoamericanas esta planificación urbana que no tuvo en cuenta el lugar, generó exclusiones y diferencias de clases sociales propias del mundo colonial, aplicadas al mundo contemporáneo, no solamente en la planificación territorial, sino también en las ideas y formas de pensamiento que acompaña la delimitación de las ciudades actuales y sus formas de habitarlas. En el caso de la Bogotá actual, la división de la ciudad en nortesur, es la misma división territorial e imaginada de clases sociales que se ubican de acuerdo a su estrato social en unos lugares y no en otros y con ello se repite el pensamiento colonial de exclusión y distanciamiento que de igual manera excluye prácticas o manifestaciones de carácter popular en el ámbito de las artes y en el ámbito patrimonial no son estudiadas ni reconocidas en este marco normativo sin muchas aplicaciones en territorios de bordes/periferias.

\section{Desarrollo de la investigación: Apuntes metodológicos de la investigación y desarrollos}

Tanto el patrimonio cultural inmaterial como el patrimonio material, van ligados a su forma de producción. Cada patrimonio es producto de un contexto histórico que define condiciones sociales, relaciones interpersonales en las cuales las redes que se establecen y los recuerdos, memorias, 
documentos entretejen un patrimonio colectivo reconocible como tal. Los asentamientos urbanos periféricos tienen formas de ocupación no controlada, donde además de generar una constante necesidad de vivienda, se producen prácticas culturales, que están en relación con las migraciones, las culturas y tradiciones rurales o de otros barrios periféricos que vinculan diferentes actores del espacio urbano y que con el paso del tiempo crean una habitación del espacio público y una vida cotidiana en el espacio urbano.

\section{Tipos de patrimonio}

La noción de patrimonio es importante para la cultura y el desarrollo en cuanto constituye el "capital cultural" de las sociedades contemporáneas. Según los indicadores de UNESCO (2020) de la cultura para el desarrollo, los tipos de patrimonio se definen como:

Patrimonio cultural inmaterial: aquellos usos, representaciones, expresiones, conocimientos y técnicas - junto con los instrumentos, objetos, artefactos y espacios culturales que les son inherentes - que las 1. Los sitios naturales pueden pertenecer al patrimonio cultural, pues la identidad cultural está estrechamente relacionada con el medio ambiente natural en el que se desarrolla. Los ambientes naturales llevan la huella de miles de años de actividad humana y su apreciación es, sobre todo, una construcción cultural.

Patrimonio Cultural: El patrimonio cultural encierra el potencial de promover el acceso a la diversidad cultural y su disfrute. Puede también enriquecer el capital social conformando un sentido de pertenencia, individual y colectivo, que ayuda a mantener la cohesión social y territorial. Por otra parte, el patrimonio cultural ha adquirido una gran importancia económica para el sector del turismo en muchos países, al mismo tiempo que se generaban nuevos retos para su conservación.

Patrimonio natural: i) los monumentos naturales constituidos por formaciones físicas y biológicas o por grupos de esas formaciones que tengan un valor universal excepcional desde el punto de vista estético o científico; las formaciones geológicas y fisiográficas y las zonas estrictamente delimitadas que constituyan el hábitat de especies animales y vegetales amenazadas, que tengan un valor universal excepcional desde el punto de vista de la ciencia o de la conservación, los lugares naturales o las zonas naturales estrictamente delimitadas, que tengan un valor universal excepcional desde el punto de vista de la ciencia, de la conservación o de la belleza natural.

Las culturas que se presentan en un territorio son por lo general el producto de esfuerzos comunitarios por no dejar morir tradiciones, formas de ver el mundo, auto miradas. La cultura va por dos vías: la de la acomodación y la de la resistencia. Con la entrada del capital, la segunda tiene dificultades para desarrollarse plenamente y debe provenir de los márgenes. En un lado de la "línea abisal" tenemos lo que críticos, opinadores y revistas han constituido como el canon. Y esto fue creado para servir a la sociedad metropolitana. (Boaventura de Sousa Santos, 2019 Pág. 2).

El entorno de barrio informal, conlleva una movilidad en la cual circula la vida cotidiana, que depende de la migración o desplazamiento territorial y contiene culturas del lugar, que se movilizan hacia las ciudades informales, si bien existen tradiciones regionales en festivales en los barrios informales que hablan del desplazamiento no solamente de vivienda, sino de nuevas formas de habitar un territorio específico. La relación entre la forma de asentamiento y la producción de un patrimonio inmaterial presentan tendencias a la gentrificación y contienen historias cotidianas de inmigración de territorios a las ciudades, en organizaciones de apoyo social o comunitario que encuentran en la celebración y festividades como carnavales, fiestas o celebraciones una nueva forma de cohesión social y de identidades móviles entre lugares, recuerdos y nuevos asentamientos. 


\section{Apuntes metodológicos de la investigación}

Esta investigación busca sistematizar prácticas culturales inmateriales que existen en diferentes barrios en la localidad de san Cristóbal, al suroriente en la ciudad de Bogotá. Las principales fuentes, son orales, ya que, aunque existen registros (más de carácter publicitario) en diferentes redes sociales, y existen pocos archivos organizados en las organizaciones culturales. La entrevista oral, como instrumento acoge elementos de la etnografía que al ser aplicados al mapeo social permiten entender una determinada práctica social.

La cartografía social es un método que incluye poblaciones diversas en una investigación, de carácter participativo, mediante la cual se entiende que la realidad es construida culturalmente por las personas, desde sus experiencias de patrimonios culturales inmateriales que presentan memorias, y permiten rastrear desde sus experiencias culturales, artísticas que se desplazan de un entorno a otro, de acuerdo a procesos migratorios, es el caso de este territorio.

El uso de instrumentos como la realización de mapas permite entender diferentes tipos de saberes que vienen del conocimiento del lugar de los habitantes que participan en su elaboración. Cada encuentro recupera recuerdos de colectividades que habitan un lugar, si bien este tipo de ejercicio colectivo, permite entender una auto representación de un grupo en particular, existen otras actividades dentro del mapeo, como el participar activamente de eventos para encontrar los protagonistas que hacen parte de una comunidad cultural y las redes culturales que participan en su construcción cultural.

Este proceso de investigación, ha requerido una inmersión en un espacio físico, virtual, y una estrategia para guardar memorias y contribuir a la creación de las fuentes primarias a futuro está la imagen fotográfica como el testimonio oral (grabación). Tanto la imagen fotográfica, como el testimonio oral son resultados de esta investigación y presenta nuevos ejes de trabajo a futuro que permitan completar publicaciones con otros tipos de fuentes que integren mayores trabajos en la Localidad post-pandemia, 2021.
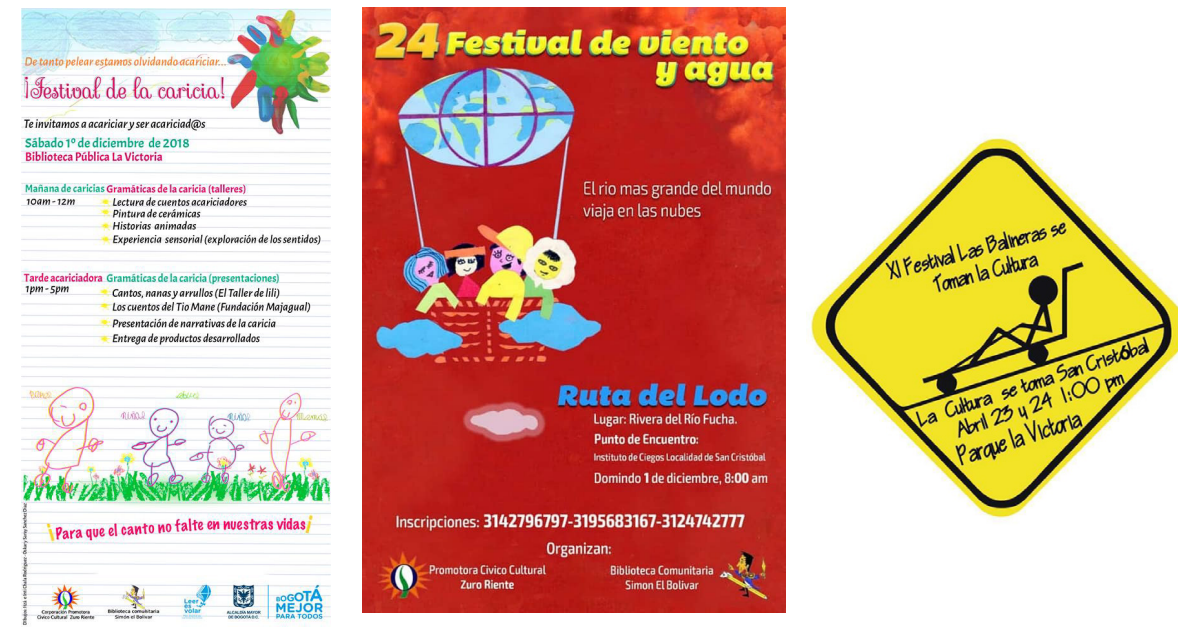

Figura 1: Carteles publicitarios de organizaciones culturales de la localidad de San Cristóbal. Fuente: Red de Eventos de la Localidad de San Cristóbal, iniciativa que lleva años trabajando en regular y participar en la asignación de recursos que brinda la Alcaldía local al sector cultural. un esfuerzo comunitario en la gestión de eventos.

En los barrios de la Localidad de San Cristóbal, las formas de asociación cultural, recrean vestigios sociales, memorias del pasado que se reactualizan en un presente en transformación, la 
extensión numérica no solamente de barrios, sino de habitantes, es extensa y permite continuar a futuro con investigaciones detalladas que brinden más categorías y un panorama más amplio en el tiempo y espacio.

El espacio urbano como espacio social, alude a las formas de representación en festividades, carnavales y prácticas artesanales de carácter comunitario. Los festivales han iniciado en distintos barrios de carácter informal. Los festivales y las fiestas son aquellas celebraciones que recuerdan un momento del pasado que reafirma una identidad colectiva, en ocasiones llevan rituales construidos con el tiempo, en otros casos reúnen celebraciones que recuerdan momentos de otros lugares o regiones.

Los festivales realizados en la localidad con la perspectiva histórica, permite entenderlos como parte de un rescate de memoria que incluye diversas poblaciones. En el caso del Festival del Maíz, se inició en el barrio San Rafael, pero con el tiempo se han integrado otros barrios como Juan Rey, Los Puentes, San Cristóbal, Libertadores, Londres, guacamayas y Altamira. La idea de realizar un evento como la Semana del Maíz nace en el año de 1990 a raíz de un conversatorio y encuentro con comunidades indígenas en el marco del encuentro nacional de la ONIC (Montalbán, 2003 Pág. 12).

La migración de poblaciones de diferentes lugares del país, en especial de diferentes comunidades indígenas, generan un desplazamiento por situaciones de violencia. Los festivales y carnavales como actividades festivas rememoran prácticas alimenticias tradicionales de comunidades indígenas en un tránsito al mundo urbano y en este caso, en un ámbito de borde.

Las prácticas festivas inmateriales en espacios autoconstruidos, se entienden en continua transformación, siempre en un esfuerzo inacabado o en constante cambio y variación, que identifica el lugar con un carácter popular en su arquitectura que plantea un nuevo diseño arquitectónico en los barrios desde la parte baja a la parte alta de la localidad. En este plano se ubican los espacios culturales en los barrios en los que funcionan en la Localidad 4 de San Cristóbal, en relación a estos espacios culturales en relación a prácticas patrimoniales de carácter inmaterial:

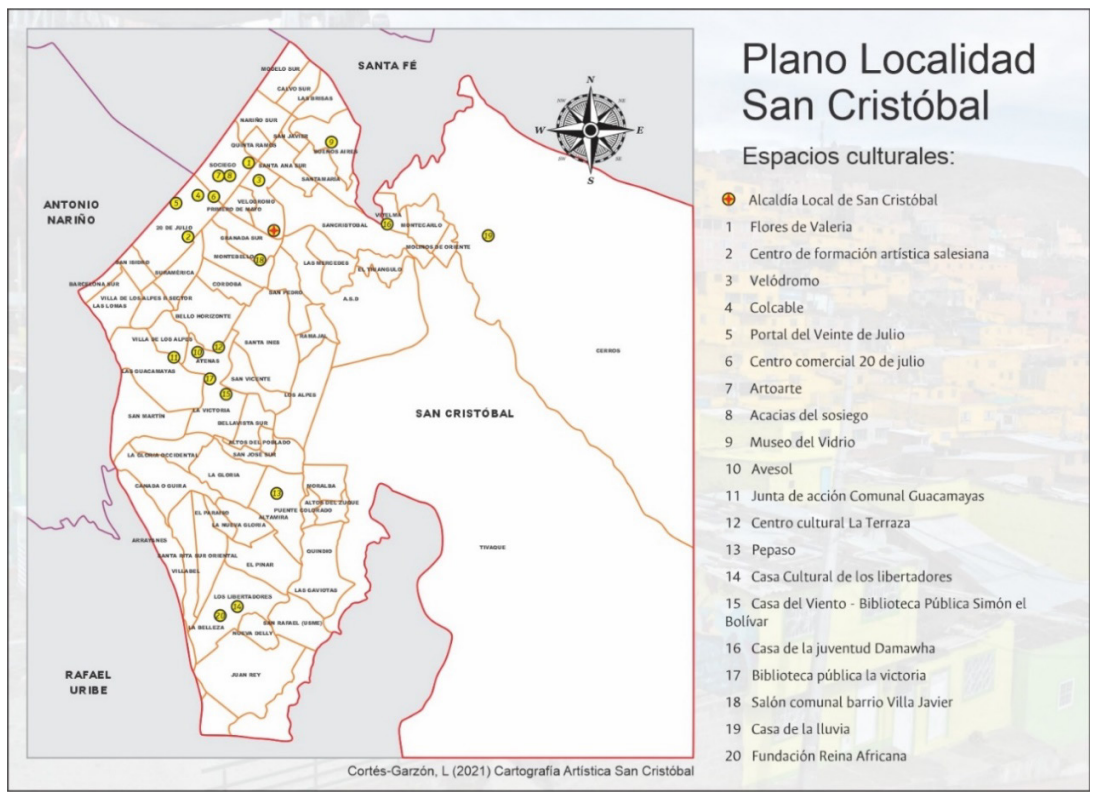

Figura 2: Espacios culturales de la Localidad de San Cristóbal. Fuente: Elaborado por el autor, 2021. Cartografía artística de San Cristóbal. Bogotá, Colombia

Este mapeo de prácticas en lugares específicos de la Localidad de San Cristóbal, permite mapear 
en futuras investigaciones las practicas artesanales en peligro de extinción, es el caso del trabajo del vidrio y los artesanos que desarrollan diferentes técnicas como el soplete o el soplado.

El Taller de los hermanos Conde (Carlos Conde es su fundador) recupera una de las tradiciones de la Localidad: El trabajo en Vidrio soplado, una técnica que hace pocos años estaba en riesgo. Realizan figuras en especial miniaturas que realizan para la venta: Pipas, animales algunas lámparas. En la localidad hay algunos documentos en revistas y fanzines de finales del siglo XIX Y principios del siglo XX que hablan ya del oficio del vidrio en este lugar. Las prácticas artesanales, por una parte y las prácticas artísticas que llegan como un desplazamiento de saberes en memorias móviles se adaptan a los lugares que migran de acuerdo a sus mismas migraciones.

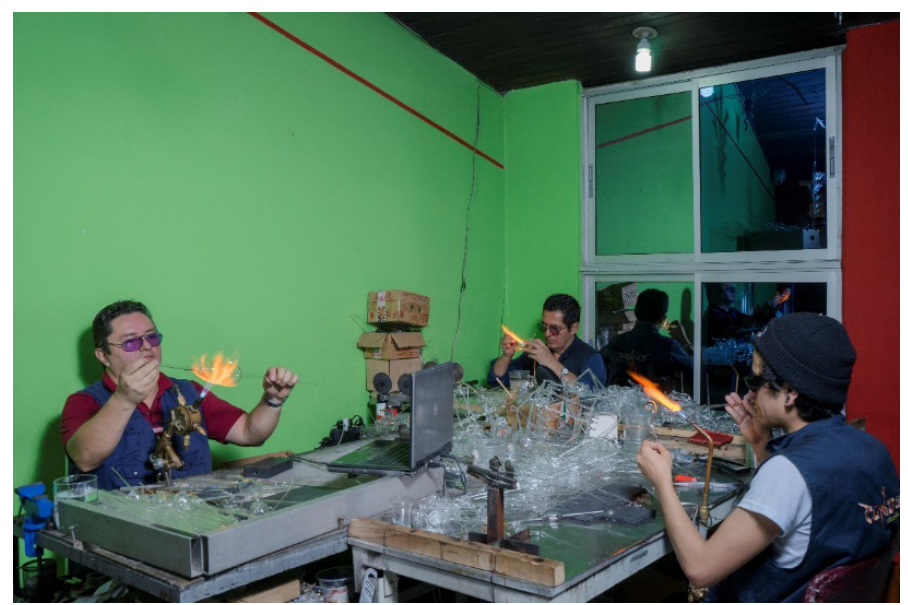

Figura 3: Fotografía de Taller de vidrio. Fuente: Millán, A. Cortés, L, 2019. Taller de maestros Conde. Técnica vidrio soplado. Localidad de San Cristóbal.

\section{Resultados}

Como parte de la categorización de las prácticas culturales inmateriales en la localidad del sur oriente de la ciudad de Bogotá, se registraron fotografías, como fuentes primarias que documentan agrupaciones y colectivos en prácticas culturales y artísticas. Son protagonistas de las prácticas de cultura inmaterial y su categorización visual busca entrar a crear documentos visuales, no solamente escritos, que permitan una mirada desde la creación en el ámbito de la investigación y en el campo de la creación.

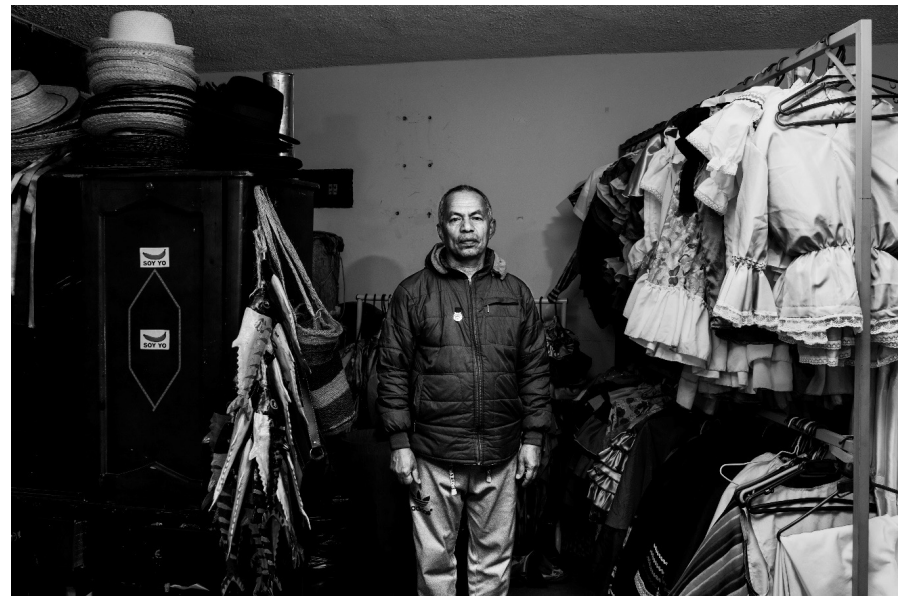

Figura 4: Fotografía Arnedis Rancero Gestor cultural y bailarín. Fuente: Millán, A, Cortés-Garzón, L (2019) Arnedis Rancero. Localidad de San Cristóbal. 

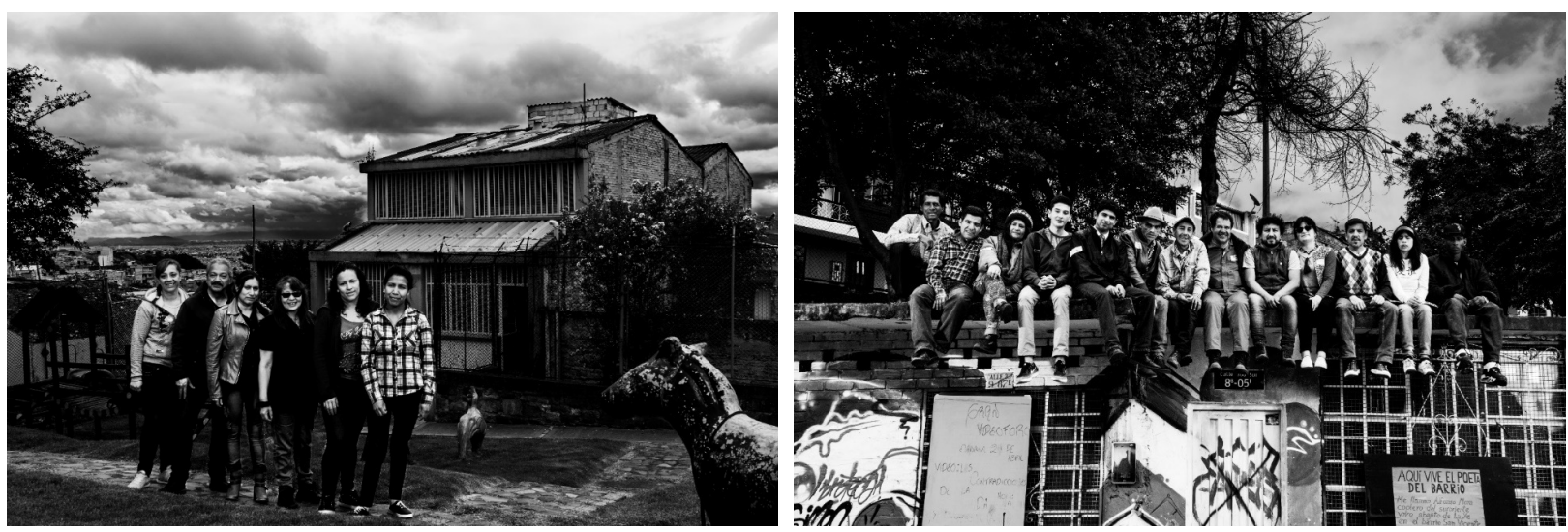

De izquierda a derecha. Figura 5: Fotografía integrantes de la organización Avesol. Fuente: Millán, A, CortésGarzón, L., 2019.Avesol. Localidad de San Cristóbal. Figura 6: Fotografía de Organización cultural. Fuente: Millán, A, Cortés-Garzón, L., 2019. Miembros del colectivo Promotora cultural- biblioteca Simón El Bolívar. Localidad de San Cristóbal.
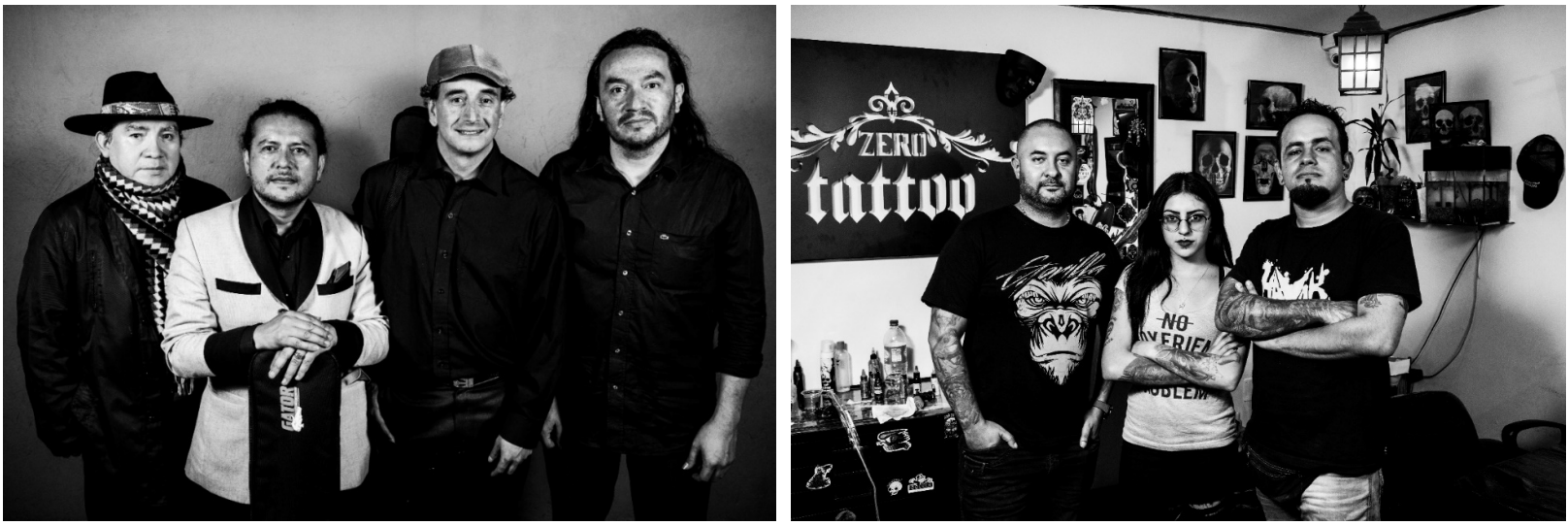

De izquierda a derecha. Figura 7: Fotografía músicos locales. Fuente: Millán, A, Cortés-Garzón, L., 2019. Grupo Origen Ensamble. Localidad de San Cristóbal. Figura 8: Centro Comercial 20 de Julio. Fuente: Millán, A, CortésGarzón, L., 2018. Zero Tatoo. Prácticas visuales de Tatuaje en el centro comercial del Barrio Veinte de Julio. Bogotá.
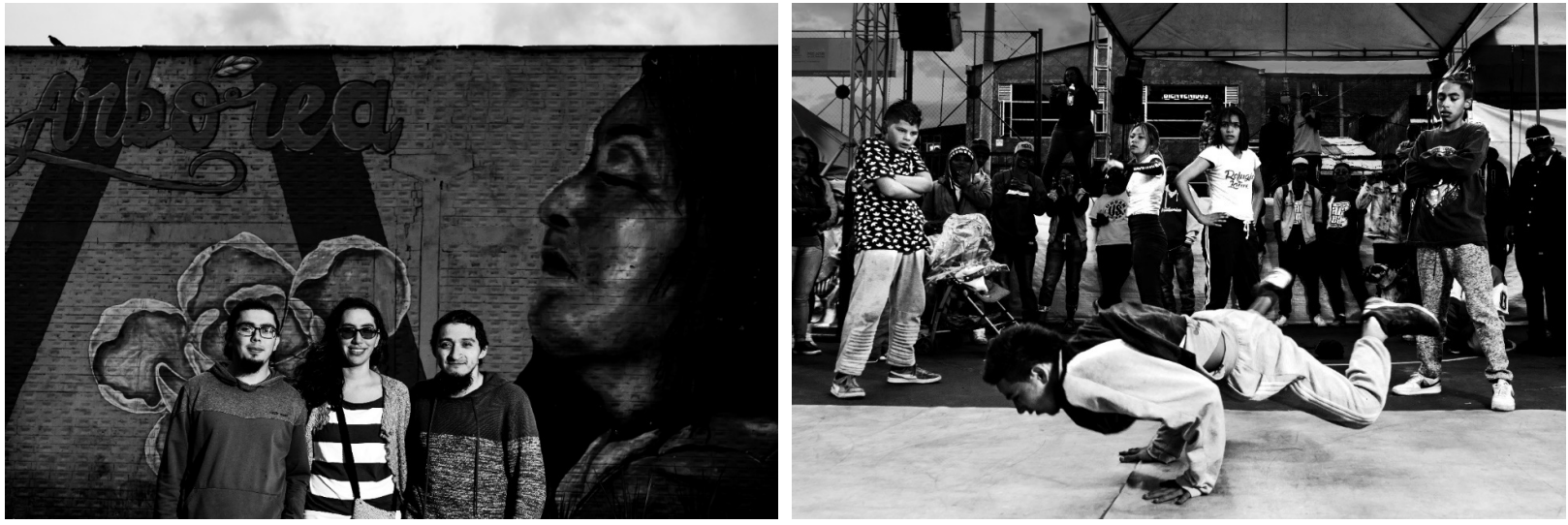

De izquierda a derecha. Figura 9: Artistas locales: muralistas. Fuente: Millán, A, Cortés-Garzón, L (2018). Colectivo Artoarte en la Localidad 4 de San Cristóbal, Bogotá. Figura 10: Fotografía Bailes urbanos. Fuente: Millán, A, CortésGarzón, L (2018). Break dance, Barrio La Victoria, Localidad de San Cristóbal. Bogotá. 
Se realizó la siguiente categorización de prácticas culturales en cuanto Patrimonio inmaterial en la Localidad de San Cristóbal:

Tabla 1: Cuadro categorización de prácticas culturales. Fuente: Elaborada por el autor, 2021. Categorías de Patrimonio Cultural Inmaterial Localidad Cuarta de San Cristóbal Bogotá-Colombia

\begin{tabular}{|c|c|c|c|c|c|}
\hline \multicolumn{6}{|c|}{$\begin{array}{l}\text { Tipologías de prácticas culturales inmateriales } \\
\text { Localidad Cuarta (4) San Cristóbal }\end{array}$} \\
\hline $\begin{array}{l}\text { Festivales/ } \\
\text { Carnavales }\end{array}$ & Música & Baile & $\begin{array}{l}\text { Artes Plásticas } \\
\text { y visuales }\end{array}$ & $\begin{array}{l}\text { Prácticas } \\
\text { conservación } \\
\text { naturaleza }\end{array}$ & $\begin{array}{l}\text { Prácticas } \\
\text { artesanales }\end{array}$ \\
\hline $\begin{array}{l}\text { Festival } \\
\text { suroriental } \\
\text { de Música } \\
\text { Popular }\end{array}$ & Músicas populares & Danzas urbanas & Grafitti & $\begin{array}{l}\text { Rutas de } \\
\text { caminatas en } \\
\text { parques Naturales. } \\
\text { Entre Nubes }\end{array}$ & Trabajo en vidrio \\
\hline $\begin{array}{l}\text { Carnaval del } \\
\text { sol }\end{array}$ & Músicas urbanas & $\begin{array}{l}\text { Danzas } \\
\text { tradicionales }\end{array}$ & Pintura & $\begin{array}{l}\text { Rutas reserva del } \\
\text { Delirio }\end{array}$ & Artesanías tejidas \\
\hline $\begin{array}{l}\text { Festival del } \\
\text { viento y las } \\
\text { cometas }\end{array}$ & $\begin{array}{l}\text { Músicas } \\
\text { afrodescendientes }\end{array}$ & $\begin{array}{l}\text { Danza } \\
\text { contemporánea }\end{array}$ & Muralismo & $\begin{array}{l}\text { Caminatas reserva } \\
\text { de Sumapaz }\end{array}$ & $\begin{array}{l}\text { Cocinas } \\
\text { populares }\end{array}$ \\
\hline $\begin{array}{l}\text { Festival del } \\
\text { Agua }\end{array}$ & Ranchera & Danzas regionales & Tatoo & $\begin{array}{l}\text { Jornadas de } \\
\text { reciclaje cuenca } \\
\text { del Río Fucha } \\
\end{array}$ & cerámica \\
\hline $\begin{array}{l}\text { Festival de } \\
\text { niños y niñas, } \\
\text { Ciclo ronda de } \\
\text { la Alegría, } \\
\text { Festival del } \\
\text { Maíz, } \\
\text { Festival de las } \\
\text { Balineras, } \\
\text { Festival de la } \\
\text { caricia }\end{array}$ & Hip Нор & $\begin{array}{l}\text { Danza } \\
\text { contemporánea }\end{array}$ & $\begin{array}{l}\text { Dibujo } \\
\text { Performance } \\
\text { Vídeo }\end{array}$ & Agricultura urbana & Trabajo en piedra \\
\hline
\end{tabular}

Como categorías del patrimonio inmaterial de la Localidad de San Cristóbal en el suroriente de la ciudad de Bogotá, se encuentran los festivales y carnavales como una de las manifestaciones y prácticas, más recurrentes en el espacio público. Si bien con la pandemia actual Covid-19, estas manifestaciones se redujeron y hicieron un paso a encuentros virtuales, se configuran como prácticas del recuerdo, que conservan una memoria del lugar de origen de sus habitantes. De igual manera, existen prácticas artísticas que son hibridas, ya que entremezclan tradiciones culturales originarias con las prácticas propias del ámbito urbano, en este caso las músicas urbanas que presentan diversos géneros musicales: rap, hip-hop, rancheras, músicas de origen popular y unas pocas iniciativas en formación de públicos en música clásica. Las prácticas artesanales, son actividades que refieren como categoría a la elaboración de artesanías y objetos en vidrio. En la localidad de San Cristóbal, desde finales del siglo XIX, se asentaron algunas fábricas y trabajo en vidrio, que se ha mantenido en prácticas artesanales en vidrio, que han subsistido en el paso del tiempo. Hay un interés muy visible en trabajos de formación para la conservación de reservas naturales, en el caso de la reserva entre nubes en la parte alta de la localidad, actividades que se realizan en relación con el medio 
ambiente, la conservación del río, de las cuencas hidrográficas que benefician el ámbito rural en el borde de la localidad, como son las salidas, los recorridos, las reflexiones en conversatorios sobre la protección de la naturaleza y la prevención en la contaminación generada por el mal uso de basuras, de desechos, entre otras actividades. A lo largo de las últimas décadas, el trabajo de gestión comunal ha creado organizaciones culturales que trabajan en la consolidación de espacios culturales que benefician a públicos de diferente rango de edad.

\section{Recomendaciones}

La protección del patrimonio inmaterial en barrios informales en el caso de San Cristóbal en Bogotá, requiere ser sistematizado en escritos que permitan guardar la memoria de las acciones existentes en los mismos. Es importante, destinar una parte de los presupuestos locales de la Alcaldía a una serie de investigaciones que terminen en libros sobre la localidad. Aunque las fiestas, celebraciones y festivales son constantes, a pesar de la pandemia Covid-19 es importante que además del canal de WhatsApp que logra reunir a un gran número de artistas, gestores y artesanos, se organicen nuevos medios de comunicación que permitan en el ámbito escrito reflexionar a fondo sobre los eventos realizados en la Localidad. Un repositorio de información sistematizado es una necesidad para centralizar los documentos que se producen como resultado de actividades de patrimonio inmaterial que estuviese a disposición en internet de manera constante para su consulta.

Si bien la Biblioteca de la Victoria, mantiene algunas de las publicaciones físicas, pocas de las experiencias de los grupos culturales son sistematizadas para publicaciones consultables. Las acciones, prácticas y costumbres, tienen una tradición oral, que requiere más trabajo escrito, con el fin de preservar la memoria de patrimonios locales, como el trabajo en vidrio, las prácticas musicales desde la popular, lo urbano a lo clásico; la preservación de las prácticas abordadas en esta investigación requieren de un apoyo de sus miembros de acuerdo a sus memorias locales, de igual manera compartir de acceso libre, los documentos, fuentes primarias y secundarias para futuras investigaciones.

¿Cómo hacer que estas prácticas patrimoniales persistan a través del tiempo? Según Gándara (2018), es importante es divulgar los patrimonios locales para protegerlos. La "divulgación significativa" es una variante de la divulgación que, como estrategia de comunicación educativa, busca educar acerca del patrimonio, con énfasis en el patrimonio cultural. Es importante generar estrategias educativas en las poblaciones de la localidad para de esta manera a partir de su difusión, proteger los patrimonios locales.

\section{Conclusiones}

Esta investigación logró iniciar la categorización de las prácticas culturales patrimoniales inmateriales, producidas en la Localidad cuarta de San Cristóbal al suroriente de Bogotá. Este trabajo de investigación, inicia un proceso de documentación y análisis en el patrimonio inmaterial, con el fin de visibilizar y ampliar el análisis de las características específicas, en lugares de borde y periferias urbanas que articulan formas culturales y actividades en el ámbito patrimonial inmaterial en barrios informales.

Las prácticas patrimoniales inmateriales se han visto alteradas y afectadas por la situación de pandemia del Covid-19, en especial por la falta de trabajo en el Espacio público (parques de bolsillo o plazas enfrente de lugares comerciales). La producción de eventos anuales en los cuales participan todo tipo de públicos como festivales, carnavales y tienen medios de comunicación: la 
emisora Vientos stéreo 94.4 FM, en especial, en el caso de la música popular, el público escucha los artistas e impulsa sus carreras artísticas en eventos y entrevistas en Colcable el canal televisivo de la localidad, se han visto afectadas y en algunos casos suspendidas, en otros se han reinventado en espacios por redes sociales.

Lo inmaterial como patrimonio y memoria de una serie de costumbres y hechos artísticos y culturales, en la localidad cuarta, presenta gran cercanía con movimientos urbanos que buscan autoidentidades en barrios de carácter informal. La construcción del territorio cultural suroriental presenta sentimientos, experiencias y prácticas urbanas tanto en espacio público que identifica el lugar como una identidad cultural resignificando experiencias comunitarias desde un nuevo simbolismo identitario o un nuevo espacio virtual como una nueva esfera pública, permite entenderse como un territorio de borde que establece una nueva forma de autodeterminación cultural y artística a partir de la consolidación de redes como el WhatsApp de Infocultura San Cristóbal que informa, comparte y da a conocer las principales actividades o hechos urbanos en la localidad, con ello permite una apropiación cultural de la ciudad suroriental en sus habitantes, con una nueva producción de sentido colectivo y cultural.

Como memorias migrantes es importante entender que el desplazamiento territorial lleva consigo el patrimonio construido, de tal manera que una característica importante en el caso de la forma de habitar un espacio en la Localidad de San Cristóbal es un espacio que constituye un nuevo patrimonio en el lugar mismo del desplazamiento. Algunas memorias que migran de lugar, tratan de tradiciones muy antiguas, otras constituyen un desplazamiento de los medios de comunicación global a lo local, es el caso de las prácticas artísticas en relación a músicas urbanas que llevan formas de baile y un "estilo" de vida que desplaza y mantiene tradiciones culturales globales.

Partir de los Estudios del sur, permite categorizar nuevas prácticas en territorios poco visibilizados en el campo patrimonial, como son los territorios de borde y periferias de las grandes ciudades latinoamericanas. Las dinámicas festivas que presenta gran actividad patrimonial inmaterial, las prácticas son continuas y muy variadas, y ello permite entender que las dinámicas sociales tienen ejes de trabajo que buscan interrelacionar las prácticas urbanas, culturales y humanas en nuevas formas de habitar un lugar, un territorio. La metodología de los mapeos sociales, da nuevas herramientas que permite llegar a geolocalizar prácticas de patrimonio inmaterial de gran importancia para preservar la memoria de los individuos y colectivos sociales.

La divulgación educativa que se da en la localidad, puede planificar, nuevas estrategias de visibilización del patrimonio cultural inmaterial y así generar procesos educativos al interior de colegios, centros educativos o de carácter artístico para conservar la memoria de las prácticas culturales y artísticas locales.

\section{Bibliografía}

AA. VV. (2018). Plan Nacional de Salvaguardia del Patrimonio Cultural Inmaterial, Madrid, Ministerio de Cultura.

Albino, J (2019). Comunicación personal realizada el Bazar del Veinte de Julio el 9 de enero 2020.

Certeau, M. de (2008). La invención de lo cotidiano (Vol. 1) Artes de hacer. México: Universidad Iberoamericana- CEMCA.

De Castro, A (2019). Comunicación personal realizada en el Barrio Veinte de Julio el 4 de mayo 
$\operatorname{del} 2020$

De Sousa Santos, B (2019). Justicia entre saberes: Epistemologías del sur contra el epistemicidio. Editorial Morata, Madrid.

De Sousa Santos, B; Meneses, M (2014). Epistemologías del sur (Perspectivas) Ed Akal, Madrid

Duarte, N y Talavera, H (2018). Bordes Urbanos. Procesos de construcción territorial. Ed. Universidad Nacional de Colombia.

Gandara, M(2013).La narrativa y la divulgación significativa del patrimonio en sitios arqueológicos y museos. Núm. 54 (2013): Museografía

Gándara, M (2018). La divulgación significativa como estrategia de comunicación educativa. ETD: Educaçao Temática Digital, ISSN-e 1676-2592, Vol. 20, Nº 3

García Canclini, N. (1999). “Los usos sociales del Patrimonio Cultural”, en Patrimonio Etnológico. Nuevas perspectivas de estudio, Sevilla, Instituto Andaluz de Patrimonio Histórico, pp.16-33

Infante, A (2013). El porqué de una epistemología del Sur como alternativa ante el conocimiento europeo Fermentum. En: Revista Venezolana de Sociología y Antropología, vol. 23, núm. 68, septiembre-diciembre, pp. 401-411. http://www.redalyc.org/articulo.oa?id=70538671007

López Medina, J (2015). Des-Bordes urbanos: un concepto en construcción. Urban unboundings: a concept under construction. Hábitat y Sociedad, (8) pp. 15-41.

Martínez, J (2011). La estructura teórica Centro/Periferia y el análisis del Sistema Económico Global: ¿obsoleta o necesaria?. Revista de Economía Mundial, (29), pp. 29-59. http://www. redalyc.org/articulo.oa?id=86622169001

Merchán, H (2020). Comunicación personal realizada el 8 de mayo del 2020.

Montalbán, C (2003). Recuperación histórica de los eventos culturales de la Localidad de San Cristóbal. Alcaldía local de San Cristóbal.

Pérez-Valecillos, T; Castellano-Caldera, C (2013). Creación del espacio público en asentamientos informales: Nuevos desafíos urbanos. Revista Bitácora, 23(2), pp. 95-104. http://www.redalyc.org/articulo.oa? id=74830874012

Santos, M (2008). La naturaleza del espacio. Ed Ariel. No pág. 352 